\title{
Development of Facial Rejuvenation Procedures: Thirty Years of Clinical Experience with Face Lifts
}

\author{
Byung Jun Kim, Jun Ho Choi, Yoonho Lee \\ Department of Plastic and Reconstructive Surgery, Seoul National University Hospital, Seoul National University College of Medicine, Seoul, \\ Korea
}

Facial rejuvenation procedures can be roughly divided into face lift surgery and nonoperative, less invasive procedures, such as fat grafts, fillers, botulinum toxin injections, thread lifts, or laserbrasion. Face lift surgery or rhytidectomy is the procedure most directly associated with rejuvenation, due to its fundamental ability to restore the anatomical changes caused by aging. Various methods of face lift surgery have been developed over the last hundred years, thanks to advances in the understanding of facial anatomy and the mechanisms of aging, as well as the dedication of innovative surgeons. However, no generally applicable standard method exists, because the condition of each patient is different, and each operative method has advantages and disadvantages. Specific characteristics of the skin of Asians and their skeletal anatomy should be considered when determining the operative method to be used on Asian patients. Plastic surgeons should improve their ability to analyze the original aesthetic properties and problem areas of each patient, drawing on scientific knowledge about the aging process, and they should develop the skills necessary to perform various rejuvenative techniques. In the present article, we reviewed various face lift procedures and the current methods of modified double plane face lift, based on our clinical experience of over 30 years.

Keywords Lifting / Rhytidoplasty / Rejuvenation / Aging
Correspondence: Yoonho Lee Department of Plastic and Reconstructive Surgery, Seoul National University Hospital, Seoul National University College of Medicine, 101 Daehak-ro, Jongno-gu, Seoul 03080, Korea

Tel: +82-2-2072-2374

Fax: +82-2-3675-7792

E-mail: lyh2374@snu.ac.kr

No potential conflict of interest relevant to this article was reported.

Received: 8 Jul 2015 • Revised: 26 Jul 2015 • Accepted: 10 Aug 2015

pISSN: 2234-6163 • elSSN: 2234-6171・http://dx.doi.org/10.5999/aps.2015.42.5.521 • Arch Plast Surg 2015;42:521-531

\section{INTRODUCTION}

The demand for a youthful and attractive appearance has recently increased as the population has aged and mass media have promoted the desire for beauty. Facial rejuvenation is different from other aesthetic procedures in that it directly restores a younger appearance in patients; therefore, proper knowledge of the anatomical aspects of the aging process is mandatory. The severity of the aging process, the areas of major involvement, the character of the skin, and skeletal appearance vary among patients. Individual factors, such as the patient's expectations, the recovery time required until the patient can return to daily social ac- tivities, and the patient's economic status also influence the choice of rejuvenation method. Hence, one of the greatest difficulties surgeons face in approaching facial rejuvenation is individual diversity, in light of the plethora of technical approaches available for improving the appearance of aging faces.

Early works describing face lift surgery date from the early twentieth century. In the early stage, procedures were limited to simple skin excision and primary closure without subcutaneous undermining or deep tissue manipulation [1-4]. Subsequently, more elaborate surgical methods were developed to achieve longer lasting and more aesthetically satisfactory results. A number of studies regarding facial structure and the aging process have been 
conducted [5-9]. Bames [10] described subcutaneous undermining and skin redraping, and Skoog $[11,12]$ presented the dissection of the superficial fascial layer and platysma as a single myofascial unit. Since these early studies by the pioneers of the field, face lift procedures have evolved from subcutaneous face lifts to deeper plane face lifts (e.g., the superficial musculoaponeurotic system (SMAS), composite, subperiosteal, and double planes), as surgical procedures were technically refined and knowledge of facial anatomy accumulated [13-28].

A number of face lift procedures and their modifications have been introduced by many surgeons, but no consensus has yet been established regarding a generally superior procedure or clear indications for various surgical methods. In the field of plastic surgery, the personal viewpoint of each surgeon still strongly influences the choice of surgical method. Therefore, it is important for surgeons to be aware of the advantages and disadvantages of each operative technique, in order to ensure that they use the optimal face lift methods for their patients (Table 1).

This study describes the aging process in all facial layers and presents our experience with various face lift procedures. It focuses on double plane face lift and its modifications, which is now the technique most commonly performed in our clinic.

\section{Anatomy of the aging face}

Aging of the face occurs due to intrinsic and extrinsic processes. The intrinsic aging process occurs at the cellular level. A decrease in hormonal levels [29], the accumulation of cell waste products [29], free radical-induced damage [30], mitochondrial aging [31], the breakdown of the telomeres [32], and accumulated gene mutation [33] are all responsible for intrinsic aging. The extrinsic aging process is caused by external factors, such as the effect of common facial expressions, gravity, sun exposure, smoking, and other environmental factors [34]. Each layer of the face may undergo its own aging process. Surgeons should consider the following points when performing face lift procedures.

First, with aging, the amount of extracellular matrix proteins, such as collagen and elastin, in the skin decreases and the skin becomes thinned and friable. Therefore, the skin of an older person is susceptible to damage and prone to wrinkling [35]. Second, in various anatomic locations of the face, fat tissues exist as independent compartments. Aging processes in the subcutaneous layer occur in two ways. One is atrophy of the facial contouring fat that is located in the deeper layer. Fat pads in the temple, periorbital, and buccal areas atrophy with aging, resulting in temporal hollowness, sunken eyelids, and cheek depression. The other way is the descent of the superficial fat compartment. Descending fat is caught by retaining ligaments, aggravating folding. The ptosis of septal fat pads in the lower eyelids creates festoons and nasojugal grooves. Malar fat pads descend and aggravate the nasolabial fold. Sagging of the labiomental fat pad produces jowl deformities [36,37]. In other words, deflation of deep fat components and ptosis of the superficial fat component make aging more prominent. Third, the mimetic muscles of the face are located within the superficial fascia, and are therefore contained in the SMAS. The SMAS layer also ages. Relaxation of the SMAS layer occurs, and the tonicity of the SMAS and facial expression muscles decreases $[38,39]$. Fourth, the retaining ligaments are tree-like arranged ligamentous structures that connect the dermis and periosteum [7]. Histologically, they are condensed fibrous tissue originating from the periosteum, the fascia

Table 1. Summary of the advantages and disadvantages of each face lift procedure

\begin{tabular}{|c|c|c|c|c|c|c|c|c|}
\hline & Subcutaneous & $\begin{array}{l}\text { SMAS } \\
\text { plication }\end{array}$ & MACS & $\begin{array}{c}\text { Lateral } \\
\text { SMASectomy }\end{array}$ & $\begin{array}{l}\text { Extended } \\
\text { SMAS }\end{array}$ & Composite & Subperiosteal & $\begin{array}{c}\text { Modified } \\
\text { double plane }\end{array}$ \\
\hline Advantages & $\begin{array}{l}\text { Simple and easy } \\
\text { Low risk of FNI } \\
\text { Rapid recovery }\end{array}$ & $\begin{array}{l}\text { Simple and easy } \\
\text { Relatively low risk } \\
\text { of FNI } \\
\text { Relatively rapid } \\
\text { recovery }\end{array}$ & $\begin{array}{l}\text { Short skin scar } \\
\text { Relatively low risk } \\
\text { of FNI } \\
\text { Firm fixation on } \\
\text { DTF } \\
\text { Lower face } \\
\text { control } \\
\text { Relatively rapid } \\
\text { recovery }\end{array}$ & $\begin{array}{l}\text { Deep-tissue } \\
\text { control } \\
\text { Long-lasting } \\
\text { effect }\end{array}$ & $\begin{array}{l}\text { Deep-tissue } \\
\text { control } \\
\text { Lower face } \\
\text { control } \\
\text { Harmonious } \\
\text { rejuvenation } \\
\text { Long-lasting } \\
\text { effect }\end{array}$ & $\begin{array}{l}\text { Good flap } \\
\text { circulation } \\
\text { Midface control } \\
\text { Long-lasting } \\
\text { effect }\end{array}$ & $\begin{array}{l}\text { Low risk of FNI } \\
\text { No RL injury } \\
\text { Long-lasting } \\
\text { effect }\end{array}$ & $\begin{array}{l}\text { Relatively less } \\
\text { invasive } \\
\text { Minimal RL injury } \\
\text { Harmonious } \\
\text { rejuvenation } \\
\text { Long-lasting effect }\end{array}$ \\
\hline Disadvantages & $\begin{array}{l}\text { Lack of deep-tissue } \\
\text { control } \\
\text { Unnatural } \\
\text { appearance } \\
\text { Short duration }\end{array}$ & $\begin{array}{l}\text { Cheese wiring } \\
\text { Lack of lower } \\
\text { face control } \\
\text { Relatively short } \\
\text { duration }\end{array}$ & $\begin{array}{l}\text { Cheese wiring } \\
\text { Tissue bunching }\end{array}$ & $\begin{array}{l}\text { Increased risk of } \\
\text { FNI } \\
\text { Lack of lower } \\
\text { face control }\end{array}$ & $\begin{array}{l}\text { Technically } \\
\text { challenging } \\
\text { Increased risk of } \\
\text { FNI } \\
\text { Decreased flap } \\
\text { circulation } \\
\text { Prolonged } \\
\text { recovery }\end{array}$ & $\begin{array}{l}\text { Technically } \\
\text { challenging } \\
\text { Increased risk of } \\
\text { FNI } \\
\text { Unidirectional } \\
\text { lifting } \\
\text { Prolonged } \\
\text { recovery }\end{array}$ & $\begin{array}{l}\text { Lack of soft tissue } \\
\text { ptosis control } \\
\text { (lift lag) } \\
\text { Prolonged } \\
\text { recovery }\end{array}$ & $\begin{array}{l}\text { Relatively long } \\
\text { recovery time } \\
\text { Higher cost } \\
\left(\text { Endotine }^{\circledR}\right)\end{array}$ \\
\hline
\end{tabular}

SMAS, superficial musculoaponeurotic system; MACS, minimal access cranial suspension; FNI, facial nerve injury; RL, retaining ligament; DTF, deep temporal fascia. 
of deep facial muscles, or the SMAS. They are oriented vertically throughout all layers of the face, as they play the important role of supporting soft tissue and creating boundaries between their fixation points. With aging, attenuation of the retaining ligaments is inevitable. As a result, the retaining ligaments lose their strength, and the bulging of soft tissues between fixation points continues $[40,41]$. Fifth, bony resorption of the facial skeleton also progresses. Until early adulthood, skeletal projection increases gradually to its peak level. Subsequently, the facial skeleton undergoes resorption, especially in several areas of the superomedial and inferolateral portions of the orbit, mid-maxilla, and the pre-jowl portion of the mandibular body [42-44]. These changes cause retrusion of the overlying facial soft tissue and an increase in facial concavity.

\section{DEVELOPMENT OF FACE LIFT PROCEDURES}

\section{Classical subcutaneous face lift}

The original concept of a face lift was introduced in the early twentieth century [1], involving the simple excision of excessive skin in the lateral portion of the face. The procedure then evolved to include subcutaneous undermining and redraping of the skin flap against gravity $[10,45]$. This subcutaneous face lift procedure has several advantages. It is simple and relatively safe, because the surgical procedure takes place above the plane that contains the facial nerves, making it easy to perform, even by beginners. In addition, this technique guarantees patients' rapid postoperative recovery, and it is very useful in secondary or tertiary face-lift operations. However, a long-term postoperative effect cannot be expected because traction force relies on the superficial skin vector. The skin has an inherent property of viscoelasticity, consisting of creeping and stress relaxation [46]. Therefore, tightened skin can easily lose its tension after a subcutaneous face lift, making the longevity of the lifting effect minimal. In addition, deep facial tissues are not manipulated in the subcutaneous face lift procedure, so ptosis of the deep tissue remains postoperatively. For these reasons, a patient who has distinct ptosis of the deep facial tissue is not suitable for a subcutaneous face lift. In our experience, although the tough skin characteristics of Asians enable a relatively longer effect compared to that observed in Caucasians, Asians tend to exhibit sagging rather than wrinkling [47]. Therefore, a deeper plane face lift is usually required to maintain a long-term effect. An unnatural mask-like appearance, distortion of the earlobe or hairline, scar widening, and flap necrosis are also disadvantages of this procedure. Hence, subcutaneous face-lift is usually limited to patients who have prominent wrinkles without significant sagging deformities, or is performed in combination with other techniques.

\section{SMAS face lift}

Since Skoog [11] first described the dissection and lifting technique of the SMAS layer in 1973, various operative methods dealing with the SMAS layer have been developed. The SMAS is the superficial fascial layer composed of fibrofatty tissue, including collagen fiber and a small amount of elastic fiber, and it has a greater strength against gravity and bears more load than the skin. Therefore, a long-term postoperative effect can be expected from a SMAS face-lift, in comparison with a classical subcutaneous face-lift.

\section{SMAS plication}

In an effort to manipulate the deep soft tissue underneath facial skin, a suture plication technique for the SMAS layer was introduced. A preauricular incision is made, extending vertically to the temporal area and posteriorly to the retroauricular area. The SMAS is exposed following subcutaneous dissection, without sub-SMAS dissection. The mobile anterior SMAS is sutured onto a relatively immobile area, such as the preauricular parotidmasseteric fascia. Three stitches are usually used in the superoposterior direction. The SMAS tissue is finally trimmed to prevent bulging. The advantages of SMAS plication are that it is easy to perform, there is little risk of facial nerve injuries because no dissection is performed under the SMAS layer, and it involves a relatively short downtime. However, SMAS plication has some disadvantages. Loss of the lifting effect may occur if the sutures are pulled through the soft tissue by the cheese wiring effect. In addition, since the deeper tissue and retaining ligaments remain untouched in this technique, the long-lasting result of the lift may be limited. Finally, rejuvenation of the neck is minimal.

\section{Minimal access cranial suspension lift}

The minimal access cranial suspension (MACS) lift is an advanced form of the suture plication method. It employs the loop suture, which grasps multiple portions of the SMAS and platysma. The final anchoring point is the deep temporal fascia superior to the zygomatic arch, which is why the technique is referred to as cranial suspension [48]. Through a short scar incision, the skin flap is elevated, and multiple loop sutures are placed above the deep tissue. These loop sutures create microimbrication, or the bunching of deep soft tissue. We usually use two loop sutures: one loop to elevate the mid-cheek and jowl in the superoposterior direction and another to hold the platysma and draw the soft tissue of the neck more vertically. A third loop may be used, especially in patients with ptosis of the malar fat pad [49]. The MACS lift has several advantages. It involves a small skin inci- 
sion and limited subcutaneous dissection, resulting in rapid postoperative recovery. The absence of dissection below the SMAS plane minimizes the risk of facial nerve injury. The vertical anchoring of the soft tissue to the firm deep temporal fascia is also beneficial. The nasolabial fold, jowl, and cervicomental angle can be corrected through a MACS lift. In revision surgery after a deep tissue face lift, the MACS lift can be effective because it does not involve previously manipulated deep tissue, as only subcutaneous dissection is needed. Its disadvantages are similar to those of SMAS plication: possible loss of the effect over time, the cheese wiring effect, and potential irregularity of the skin flap due to excessive bunching of the loop sutures.

\section{Lateral SMASectomy}

The lateral SMASectomy was first described by Baker [50], and it involves the removal of the lateral portion of the SMAS located between the mobile and fixed SMAS. According to Baker, the SMAS layer is exposed through a classical face lift incision or a short scar incision, and then a strip of superficial fascia overlying the anterior border of the parotid gland is removed. The free edge of the anterior mobile SMAS is pulled superoposteriorly and sutured to that of the fixed SMAS. The vector of SMAS traction can be individualized to each patient, and can be different from the vector of skin traction. The preoperative pinching of patients' rhytids may be helpful in deciding the vector and amount of SMAS resection. Lateral SMASectomy has several advantages with regard to its safety and effectiveness. The degree of fixation between the mobile and fixed SMAS is much stronger than that in SMAS plication, and the lifting effect lasts longer. Compared with more aggressive face lift procedures that require extensive sub-SMAS dissection, such as extended SMAS lift or composite face lift, a relatively small amount of SMAS dissection is required in lateral SMASectomy. Therefore, the risk of facial nerve injury and the possibility of tearing the superficial facial layer can be reduced. The surgical technique is relatively simple, and the postoperative result is predictable. However, as in the case of SMAS plication, the retaining ligaments remain intact during lateral SMASectomy, so the advancement of deep soft tissue is limited. Performing dissection in a sub-SMAS layer involves a risk of facial nerve injury. In addition, the free cutting edges of the parotid fascia after SMAS resection should be repaired accurately to maintain its continuity.

\section{Extended SMAS lift}

Some surgeons have made efforts to elevate the skin and SMAS flaps separately and then draw each flap in an independent vector. Stuzin [22] named his technique the extended SMAS dissection. In this technique, the skin flap is elevated through a clas- sical subcutaneous face lift incision to expose the SMAS. Baker and Stuzin [51] emphasized that sufficient care must be taken to leave a moderate amount of fat intact on the superficial surface of the SMAS. During the elevation of the SMAS flap, the incision on the SMAS starts $1 \mathrm{~cm}$ inferiorly to the zygomatic arch in order to preserve the temporal branch of the facial nerve, and then the range of SMAS dissection reaches the malar fat pad and jowl areas. At this point, the zygomatic and masseteric retaining ligaments are fully released; therefore, rejuvenation of the nasolabial fold and labiomental crease is possible. Around the malar pad area, it is important to elevate the SMAS flap above the muscles, such as the orbicularis oculi and zygomaticus major and minor, because the facial nerves lie deep to the muscles. The vectors of the SMAS flap lift differ according to the targeted folds. Typically, the SMAS flap is tracted more vertically than the skin flap. In the malar fat pad area, the SMAS flap is advanced superolaterally, perpendicular to the nasolabial fold. In the jowl area, the SMAS flap is pulled almost vertical to the mandibular border. The SMAS and platysma flaps can be rotated in the postauricular area to improve the jowl and cervical contour. The extended SMAS lift has a plethora of strengths. The deep soft tissue of the face is independently mobilized from the skin, allowing a more accurate reversal of the aging process. Due to the release of the retaining ligaments and repositioning of the facial fat compartments, the lift is certain to have a long-lasting effect. In addition, the tension on the skin flap is reduced and an unnatural mask-like appearance can be avoided. The disadvantages of this procedure are its technical difficulty, the possibility of damaging facial nerves or musculature, the long operation time, and compromised skin flap viability due to extended dissection.

\section{Composite face lift}

Hamra [52,53] developed a composite face lift technique in which the skin, subcutaneous fat, and the SMAS layers are attached together and elevated as a single unit. This technique differs from the extended SMAS face lift in that uni-deep plane dissection is performed: subgaleal in the temple; sub-orbicularis oculi, sub-SMAS, and sub-platysma in the face; and pre-platysma in neck. In the extended SMAS face lift, dual plane lifting is performed, including the subcutaneous layer in the temple, face, and neck along with the sub-SMAS level in the face. We have followed Hamra's principles with little modification. In our procedures, we elevate the skin flap with subcutaneous dissection in only a limited preauricular area. Next, an incision in the SMAS is made before reaching the junction of the mobile and fixed SMAS, and then the dissection is continued in one plane below the composite layer of skin, subcutaneous fat, and the SMAS. The orbicularis oculi muscle and part of the platysma superior 
to the mandibular border are meticulously elevated as a single unit to improve the midface, lower eyelids, and labiomental crease (Fig. 1). For neck rejuvenation, supraplatysmal dissection is conducted inferior to the mandible in order to redrape soft tissue sagging. A submental incision is also made in order to tighten the relaxed platysma on both sides using a suture technique. These plication sutures toward the midline improve the contour of the blunted cervicomental angle. A major advantage of the composite face lift is that it enables the simultaneous improvement of the midface, lower eyelid, nasolabial fold, and jowl deformities [52,54]. Additionally, a single composite flap has good blood supply and is very strong, allowing it to have a long-term lifting effect. Its shortcomings include the increased possibility of facial nerve injuries, its technically challenging nature, and the limitation of advancing all layers in one direction (Fig. 2).

\section{Fig. 1. Intraoperative photograph of a composite face lift}

The overlying subcutaneous fat, skin, and platysma are dissected as a single unit. Subcutaneous plane dissection is performed below the mandible border to correct aging in the cervical region. The black arrow indicates the dissection plane below the superficial musculoaponeurotic system, and the asterisk indicates the platysma.

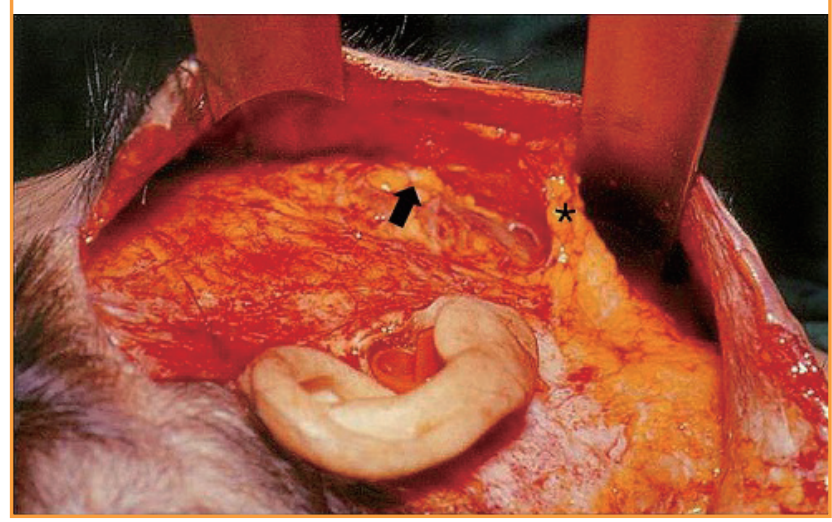

\section{Subperiosteal face lift}

Tessier $[55,56]$ first presented the concept of a face lift using the subperiosteal approach in the upper face, and this procedure has been widely used since the endoscopic technique was introduced. Ramirez et al. [28] and Ramirez [57-60] has been dedicated to using the subperiosteal plane face lift since the early 1990s, and has made it one of the essential methods for performing face lifts. This procedure has many advantages over other face lifts. First, the subperiosteal plane is safer for preserving facial nerves. According to Ramirez [61], the overall rate of facial nerve injury is approximately $2 \%$, and in almost all cases, the injuries were temporary events. Second, the subperiosteal face lift allows the repositioning of whole deep facial structures. The aging process occurs in whole layers, including the bone, as discussed above, meaning that periosteal tissue also needs to be repositioned. Third, subperiosteal dissection preserves the normal retaining ligamentous structure and the multiple supporting fibroelastic septa as much as possible. Fourth, it restores the tension of the superficial mimetic muscles without significantly changing the muscle length. This can minimize unnatural facial expressions compared to the SMAS lifting methods. Fifth, deep plane dissection allows maximal vascularity of the facial flap. This allows additional procedures such as a subcutaneous face lift, lipofilling, or laserbrasion to be performed safely. Finally, a long-lasting effect can be expected. A subperiosteal face lift redrapes the supporting deep facial structures en bloc in a vertical direction, such that the lift is strong against stress relaxation.

However, subperiosteal dissection alone has difficulty in lifting the lower face and correcting jowl deformities, especially in patients over 50 years of age [61]. Furthermore, the amount of lifting by a subperiosteal vector is not delivered equally to the superficial soft tissue due to relaxed retaining ligaments. The

\section{Fig. 2. Preoperative and postoperative photographs of composite face lift}

A 65-year-old woman $(A, B)$ preoperatively and $(C, D)$ three years after a composite face lift.
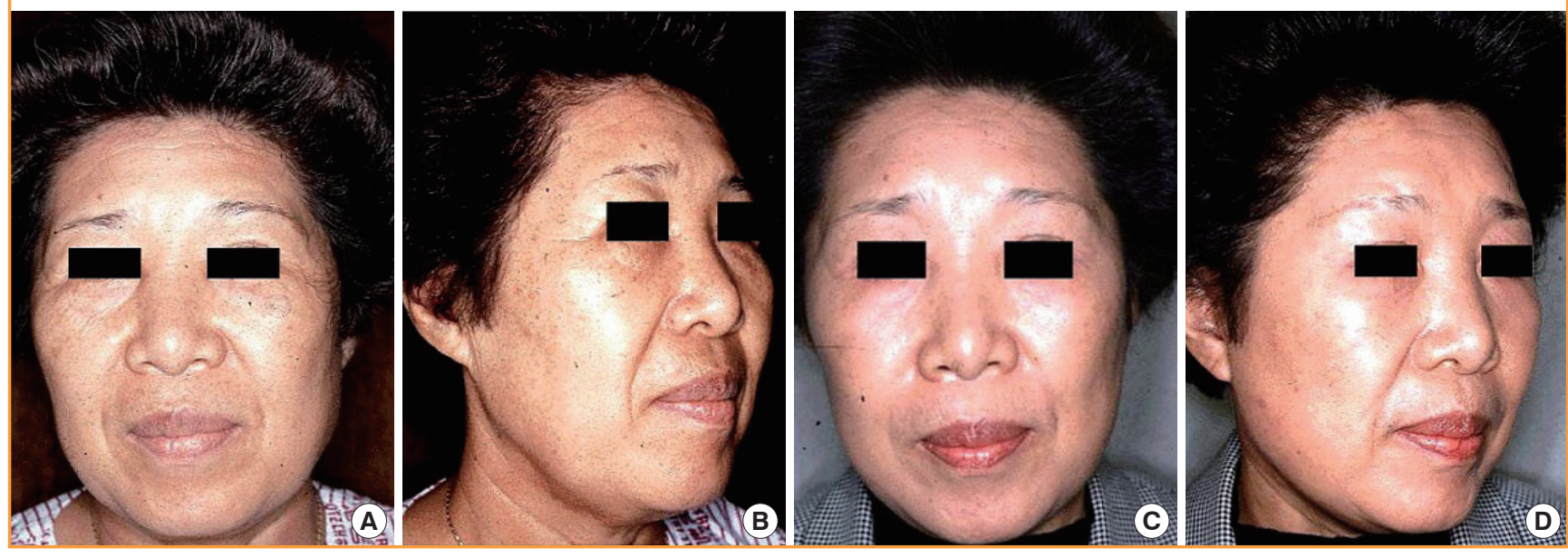
maximal effect can be achieved when the subperiosteal face lift is combined with the superficial plane face lift, which is a double plane face lift.

In the early stage of our clinical experience, we performed double plane face lifts using the bicoronal approach to achieve a longlasting effect and a harmonious natural appearance [62]. Briefly, after bicoronal incision, subperiosteal dissection was performed in the nasal and zygomatic areas. Subfascial dissection was meticulously conducted on both temporal sides, taking care not to cause injury to the frontal branch of the facial nerve. The corrugator supercilii, procerus, and part of the frontalis muscle were resected from the frontal flap in patients with severe glabella and forehead wrinkles. Bilateral upper buccogingival incisions were made, and subperiosteal dissection was continued over the maxilla and zygoma to connect with the subperiosteal pocket of the temporal side. After complete subperiosteal dissection and vertical lifting of the midfacial flap, multiple suspension sutures were anchored to the deep temporal fascia. The frontal flap was also vertically lifted and fixed with the periosteum of the posterior scalp. Next, conventional subcutaneous dissection was conducted. The subcutaneous midface flap was lifted in a horizontal direction. We achieved aesthetically satisfying results that lasted for a long time, although prolonged swelling and edema were the main complaints (Fig. 3).

\section{Modified double plane face lift}

Conventional double plane face lifts show aesthetically satisfying results that last for a long time. Ramirez [61] reported his personal experiences with a subperiosteal face lift that lasted for over 10 years. However, subperiosteal face lifts using the bicoronal approach require a long operation time and prolonged recovery. The risk of a frontal branch injury, temporal depression during the subfascial dissection of the temple, sensory changes in the scalp, and prominent scarring are also major problems that make this method technically challenging. Using an intraoral approach to achieve complete midface dissection causes prolonged swelling and recovery time, as well as increasing the risk of intraoral wound infection.

Recent advancements in minimally invasive surgery and the development of biocompatible materials, such as Endotine (Coapt Systems Inc., Palo Alto, CA, USA), led us to develop a modified double plane face lift that is less invasive than the conventional double plane face lift (Fig. 3). Briefly, we use an endoscopic forehead approach instead of a bicoronal approach. Two

Fig. 3. Conventional versus modified double plane face lift

$(A, B)$ Intraoperative photographs of a conventional double plane face lift and (C, D) a modified double plane face lift.
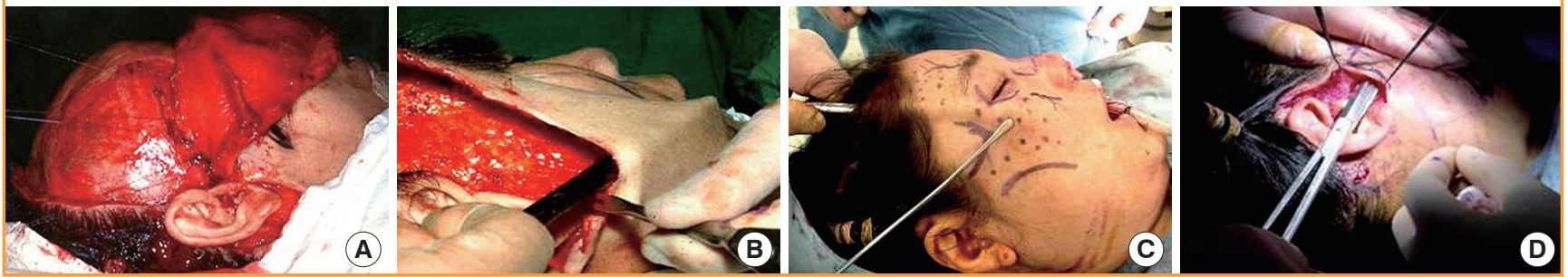

Fig. 4. The effect of face lifts on the retaining ligament

(A) The normal aging process involves soft tissue sagging with attenuation of the retaining ligament. During (B) subcutaneous plane face lift or (C) superficial musculoaponeurotic system face lift, injury to the retaining ligament is inevitable. (D) The double plane face lift with subperiosteal and subcutaneous plane dissection can minimize injury to the retaining ligaments. Blue arrows indicate the movement of soft tissue. SMAS, superficial musculoaponeurotic system.
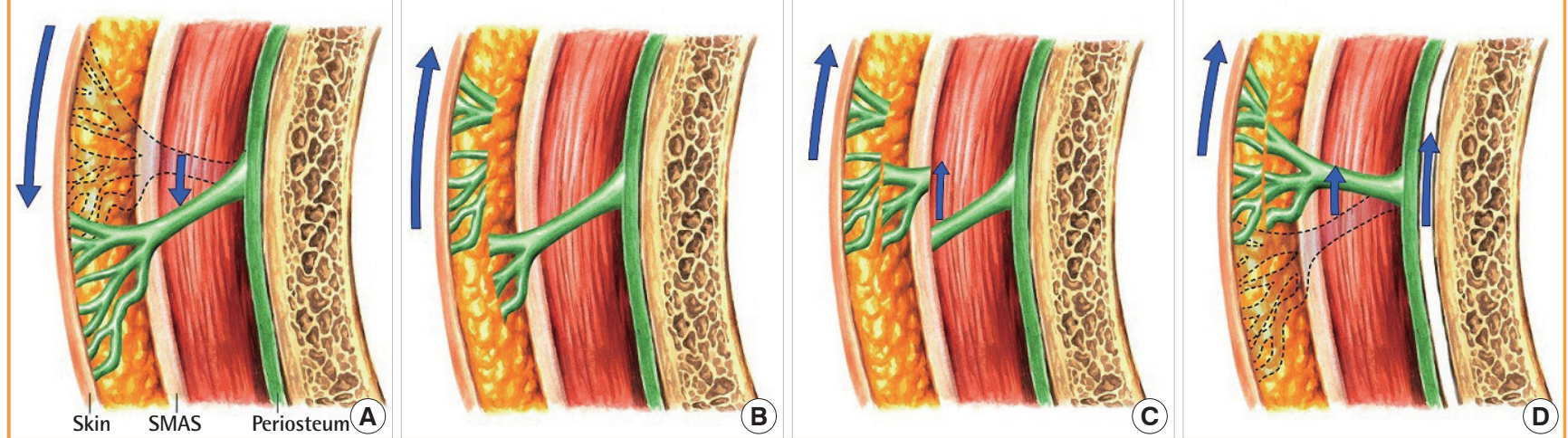
vertical incisions are made $2 \mathrm{~cm}$ posterior to the hairline. Wide subperiosteal dissection is then performed to the vertex, laterally to the temporal fusion line, and down to the nasal area and zygomatic complex. During subperiosteal dissection, complete subfascial dissection of the dangerous temporal region is not always necessary if the lateral margin of the lateral orbital rim and the upper margin of the zygomatic arch are completely dissected subperiosteally and a limited subfascial dissection of the masseteric fascia is concomitantly performed, because of the relative mobility of the temporal region itself. A bilateral intraoral ap-

\section{Fig. 5. Dissection area during modified double plane face lift}

The area marked in blue represents the subperiosteal dissection, whereas the area marked in yellow represents the subcutaneous dissection. Green represents the area of double plane dissection.

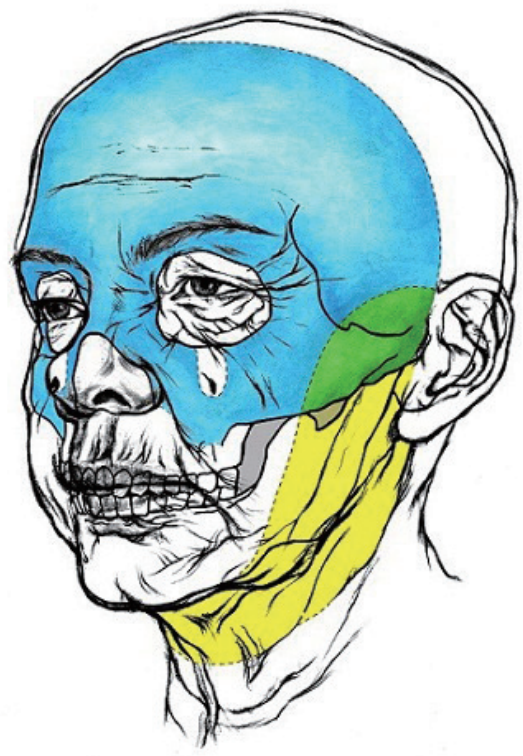

proach is not necessary if sufficient subperiosteal dissection is achieved in the zygomatic complex through the forehead approach. Subcutaneous face lift was performed to preserve the retaining ligaments, excluding the dissection of the temporal area. The retaining ligaments are released from the deeper structure using a spread technique to preserve it as much as possible. Despite debates about the necessity of retaining ligament detachment, we strongly believe that a sufficient lifting effect can be achieved by elevating the facial tissue and suspending the ligaments without causing injury to the normal retaining ligaments (Fig. 4). Subcutaneous dissection in the temple can cause bleeding, sensory loss, hair follicle injury, and distortion of the hairline and eyebrows. Moreover, deep plane dissection is sufficient to obtain adequate mobility in the temple area. The subperiosteally dissected deep tissue is lifted vertically, and fixed with the frontal bone using two Endotine devices. The subcutaneously dissected superficial tissue is lifted in a superoposterial direction vertical to the nasolabial fold. Double lifting vectors enable harmonious rejuvenation, reminiscent of the weaving of fabric (Fig. 5). Although less extensive dissection is performed in a modified double plane face lift, we have been able to achieve longterm satisfactory results not inferior to those obtained using the conventional method (Fig. 6).

\section{DISCUSSION}

Since the earliest face lift procedures were developed approximately a century ago, face lift procedures have progressed, becoming more complex and resulting in more natural yet longlasting outcomes, which have been achieved through improved knowledge of facial anatomy and accumulated clinical experi-

\section{Fig. 6. The outcomes of a modified double plane face lift}

(A, B) A 65-year-old female patient. Modified double plane face lift surgery with perioral dermabrasion was performed. (C, D) A satisfactory longterm outcome was observed two years postoperatively.
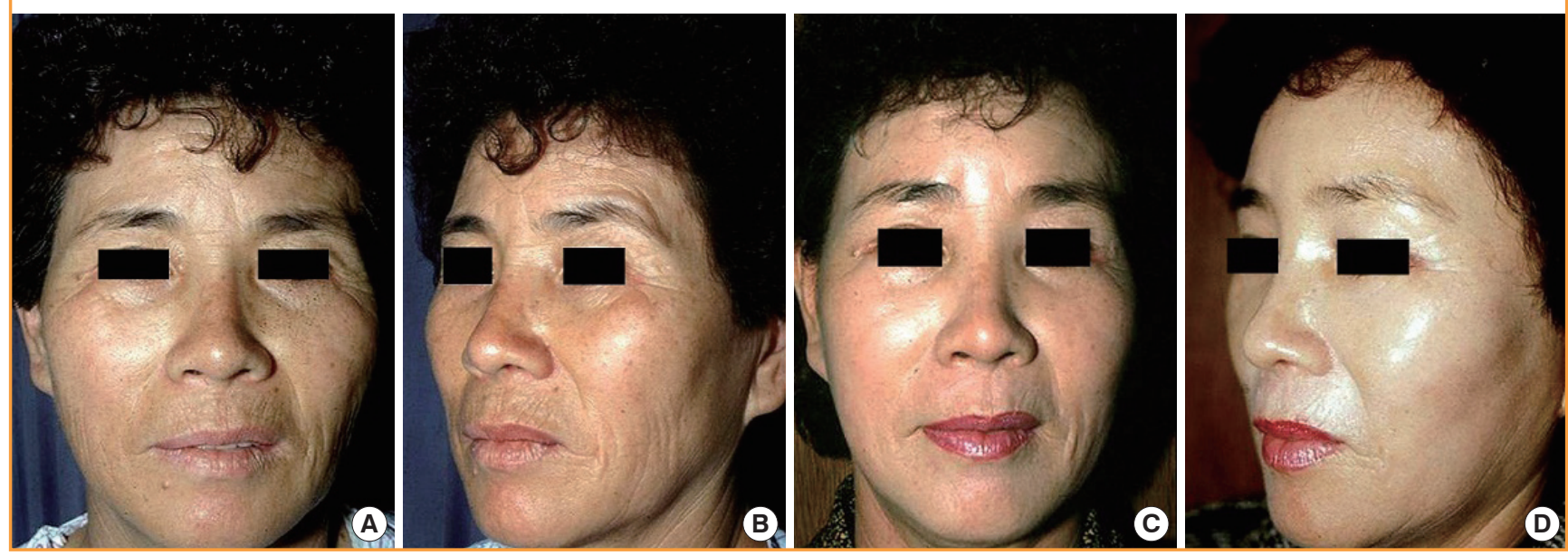
ence. Our operative methods have changed according to international trends (i.e., subcutaneous, SMAS, composite, subperiosteal, and double plane face lifts), as described in the present article. The modified double plane face lift has become our workhorse method, reflecting the specific facial anatomy of Asians, although individual differences and patients who require a quicker recovery can lead to the choice of different treatment options.

Asian patients are different from Caucasians in terms of the facial skeleton and the characteristics of their soft tissue. The facial skeleton in Asians is brachycephalic, and this population has a relatively rectangular contour with a prominent zygoma and mandible compared to Caucasians, who have a dolichocephalic skeleton and ovoid appearance [62]. This protuberance makes dissection in the subperiosteal plane more difficult in Asians,

\section{Fig. 7. The lift lag phenomenon in the subperiosteal face lift}

Simple elevation of the periosteum causes incomplete elevation of the soft tissue due to attenuation of the retaining ligament, especially in older Asian patients. $D$, lifting amount of the deep layer; $S$, lifting amount of the superficial layer.

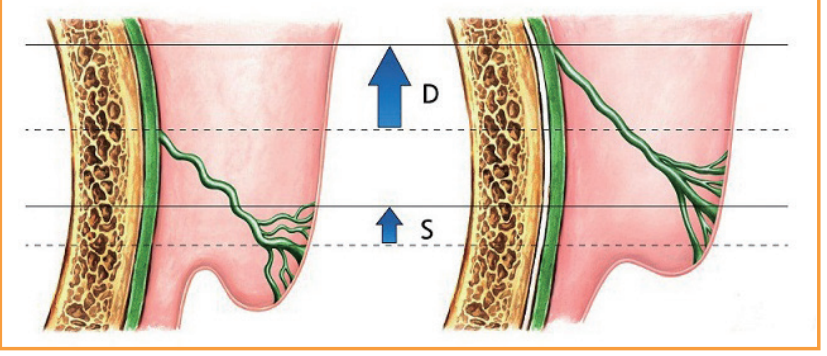

but almost complete dissection was possible in most of our cases. However, prominent zygomas are associated with a younger and more attractive appearance, leading Ramirez [60] to insert facial implants through subperiosteal dissection to augment the zygoma and improve rejuvenative outcomes in the midface. Furthermore, this prominence supports overlying the soft tissue against gravity through a fulcrum effect, meaning that a longlasting effect can be expected [62]. Soft tissue in Asians has a relatively solid attachment with the deeper tissue through fibrous septa or retaining ligaments. Additionally, Asians have thicker skin and heavier soft tissue; therefore, the sagging of soft tissue is more of a concern instead of the wrinkles or volume loss found in Caucasians [47]. These specific characters of Asians in the soft and hard tissue are indications for deep plane face lifts.

The load-carrying tissues for face lifting can be the skin, the SMAS, composite tissue, or the periosteum according to the dissection plane. The ideal load-carrying tissues should meet the following requirements: rigidity, safety, and intimate attachment with the loaded soft tissue. The effect of a skin does not last due to the stress relaxation phenomenon. The SMAS layer is better with regard to rigidity and continuity, but it is not safe to use when sub-SMAS dissection is performed. We have concluded that the periosteum is an ideal load-carrying tissue for face lifts in terms of consistency and safety in Asians.

The subperiosteal face lift is very useful in relatively young patients with minimal soft tissue sagging. However, in patients 60 years of age or older, severe soft tissue ptosis occurs in the naso-

Fig. 8. Malar fat lift using suture technique

(A-D) Intraoperative photographs and (E) scheme of the malar lift. The lifted malar fat pad is anchored to (D) the deep temporal fascia.

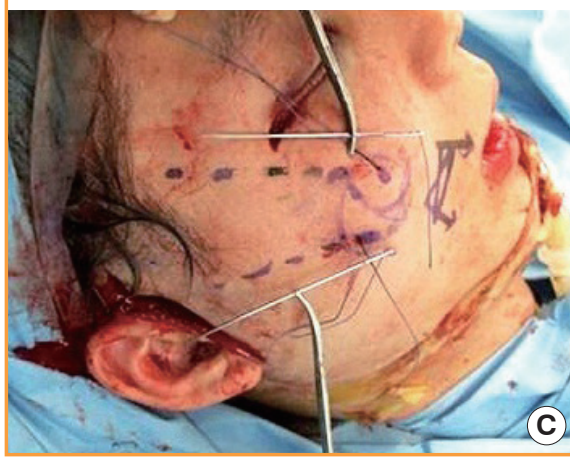

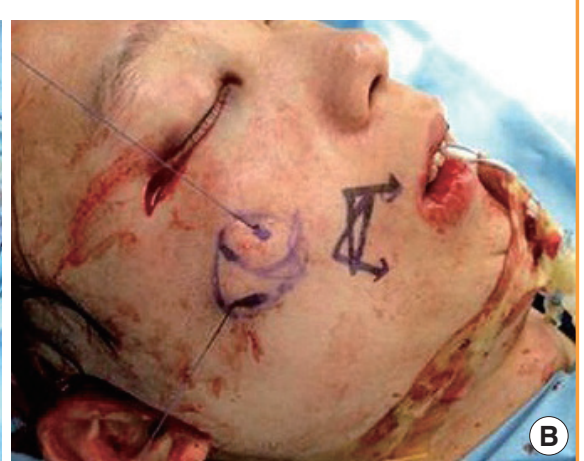

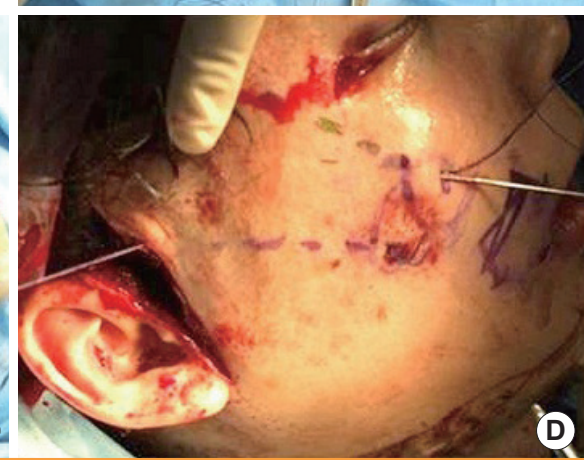




\section{Fig. 9. The outcomes of a malar fat lift}

$(A, B)$ A 62-year-old female patient with a prominent nasolabial fold. (C, D) Six months after a malar fat lift, a good postoperative result was observed. Percutaneous dimpling usually disappears within four to six weeks.
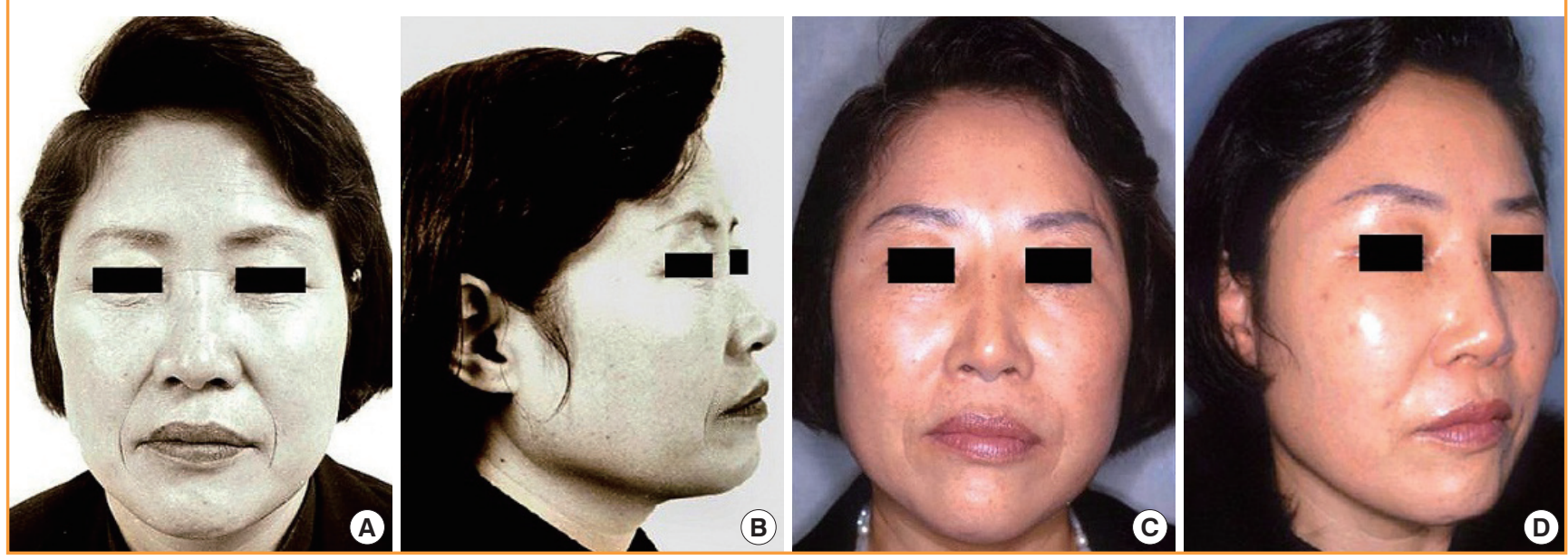

labial fold or jowls, and dermal wrinkles are present. These are difficult to correct with a subperiosteal face lift alone due to the lift lag phenomenon (Fig. 7). In other words, a single subperiosteal face lift will not improve soft tissue sagging or dermal wrinkles, because the supporting system of retaining ligaments or fibrous septa loses its rigidity and elasticity due to aging.

The double plane face lift, which combines subperiosteal and subcutaneous dissection, was a solution to overcome the lift lag phenomenon. In most cases, limited subcutaneous dissection that did not injure the retaining ligament was sufficient to improve the nasolabial fold when the underlying SMAS and facial mimetic layers are restored by subperiosteal lifting. The skin flap acts as a carrier for the descended malar fat pad, and it effectively repositions it in a superolateral direction, perpendicular to the nasolabial fold. In severe cases where the nasolabial fold does not improve with a subcutaneous plane lift, direct malar fat lifting using the suture technique can be performed (Fig. 8). Briefly, two percutaneous incisions are made on the malar area. The malar fat pad is sutured with 2-0 polydioxanone (PDS, Ethicone Inc., Somerville, NJ, USA) in a figure-eight fashion. Long straight needles are replaced in both ends of the thread. They then pass the subcutaneous layer toward the temple in a superoposterior direction. The tension of the thread is adjusted until a satisfactory result is obtained, and the thread is securely fixed to the deep temporal fascia. Although skin dimples appear in the incision area, they usually disappear within four to six weeks postoperatively (Fig. 9).

Minimally invasive procedures are also an important option for rejuvenation. Recently, interest in minimally invasive procedures has increased. Since an increased proportion of women and elderly people are employed, many patients require rapid postoperative recovery to ensure their early return to social activities. Elderly patients may fear general anesthesia due to the anesthetic risk, especially when they have underlying general diseases. Furthermore, minimally invasive techniques can be effectively performed in combination with face lift surgery, or as ancillary procedures when recurrence is found postoperatively during long-term follow-up.

We prefer techniques based on the concept of the four Rs: relaxation, refilling, reposition, and resurfacing. Relaxation is the therapeutic paralysis of the facial expression muscles using botulinum toxin. An effective outcome can be expected, especially for fine wrinkles of the forehead and upper face. Refilling refers to the supplementation of deflated facial volume using fat transfer or various kinds of fillers. One of the main mechanisms of the aging process is deflation of the deep fat pads. The appropriate supplementation of fat or fillers can effectively rejuvenate temporal depressions, hollow cheeks, or tear trough deformities. The repositioning of sagging soft tissue can be achieved with various kinds of threads that have been improved with the development of biomaterials. This can be a good alternative to operations in patients afraid of face lift surgery. Finally, resurfacing procedures using mechanical force, chemical materials, or lasers can rejuvenate fine wrinkles. Remodeling the dermal fibroblast and improving facial skin tone can create a more resilient and youthful appearance.

\section{CONCLUSIONS}

The objectives of face lift surgery do not vary significantly among surgeons. All surgeons aim to perform procedures that are effective, long lasting, technically easy, and reproducible with a rela- 
tively high safety margin. However, no standard method exists for rejuvenating faces. In addition, no clear surgical indications have been established for face lifts, although many studies have been performed to compare various face lift techniques. The modified double plane subperiosteal face lift is currently our most commonly performed procedure; however, various other surgical techniques or minimally invasive procedures should also be used according to the clinical condition of patients and individual requirements.

\section{REFERENCES}

1. Rogers BO. The development of aesthetic plastic surgery: a history. Aesthetic Plast Surg 1976;1:3-24.

2. Stuzin JM. Aging face and neck. In: Mathes SJ, editor. Plastic surgery. Philadelphia: Saunders Elsevier; 2006.

3. Joseph J. Hangewangenplastik (Melomioplastik). Dtsch Med Wochenschr 1921;47:287.

4. Lexer E. Die Gesamte Wiederherstellungschirurgie. Leipzig: JA Barth; 1931.

5. Little JW. Three-dimensional rejuvenation of the midface: volumetric resculpture by malar imbrication. Plast Reconstr Surg 2000;105:267-85.

6. Stuzin JM, Baker TJ, Gordon HL. The relationship of the superficial and deep facial fascias: relevance to rhytidectomy and aging. Plast Reconstr Surg 1992;89:441-9.

7. Furnas DW. The retaining ligaments of the cheek. Plast Reconstr Surg 1989;83:11-6.

8. Aston SJ. Platysma muscle in rhytidoplasty. Ann Plast Surg 1979;3:529-39.

9. Mitz V, Peyronie M. The superficial musculo-aponeurotic system (SMAS) in the parotid and cheek area. Plast Reconstr Surg 1976;58:80-8.

10. Bames H. Truth and fallacies of face peeling and facelifting. Plast Reconstr Surg 1927;126:86.

11. Skoog T. Rhytidectomy: a personal experience and technique. The Seventh Annual Symposium on Cosmetic Surgery at Cedars of Lebanon Hospital; Miami, FL. 1973.

12. Skoog T. Plastic surgery: new methods. Philadelphia: WB Saunders; 1974.

13. Guerrero-Santos J, Espaillat L, Morales F. Muscular lift in cervical rhytidoplasty. Plast Reconstr Surg 1974;54:127-30.

14. Connell BF. Cervical lifts: the value of platysma muscle flaps. Ann Plast Surg 1978;1:32-43.

15. Guerrero-Santos J. The role of the platysma muscle in rhytidoplasty. Clin Plast Surg 1978;5:29-49.

16. Guerrero-Santos J. Surgical correction of the fatty fallen neck. Ann Plast Surg 1979;2:389.
17. Lemmon ML, Hamra ST. Skoog rhytidectomy: a five-year experience with 577 patients. Plast Reconstr Surg 1980;65: 283-97.

18. Kaye BL. The extended neck lift: the "bottom line". Plast Reconstr Surg 1980;65:429-35.

19. Kaye BL. The extended face-lift with ancillary procedures. Ann Plast Surg 1981;6:335-46.

20. Mendelson BC. Correction of the nasolabial fold: extended SMAS dissection with periosteal fixation. Plast Reconstr Surg 1992;89:822-33.

21. Hamra ST. The deep-plane rhytidectomy. Plast Reconstr Surg 1990;86:53-61.

22. Stuzin JM, Baker TJ, Gordon HL, et al. Extended SMAS dissection as an approach to midface rejuvenation. Clin Plast Surg 1995;22:295-311.

23. Mendelson BC. Extended sub-SMAS dissection and cheek elevation. Clin Plast Surg 1995;22:325-39.

24. Barton FE Jr. Rhytidectomy and the nasolabial fold. Plast Reconstr Surg 1992;90:601-7.

25. Owsley JQ. Lifting the malar fat pad for correction of prominent nasolabial folds. Plast Reconstr Surg 1993;91:463-74.

26. Connell BF, Marten TJ. The trifurcated SMAS flap: threepart segmentation of the conventional flap for improved results in the midface, cheek, and neck. Aesthetic Plast Surg 1995; 19:415-20.

27. Psillakis JM, Rumley TO, Camargos A. Subperiosteal approach as an improved concept for correction of the aging face. Plast Reconstr Surg 1988;82:383-94.

28. Ramirez OM, Maillard GF, Musolas A. The extended subperiosteal face lift: a definitive soft-tissue remodeling for facial rejuvenation. Plast Reconstr Surg 1991;88:227-36.

29. Gavrilov LA, Gavrilova NS. The reliability theory of aging and longevity.J Theor Biol 2001;213:527-45.

30. Yokozawa T, Satoh A, Cho EJ. Ginsenoside-Rd attenuates oxidative damage related to aging in senescence-accelerated mice.J Pharm Pharmacol 2004;56:107-13.

31. Bereiter-Hahn J. Mitochondrial dynamics in aging and disease. Prog Mol Biol Transl Sci 2014;127:93-131.

32. Goyns MH, Lavery WL. Telomerase and mammalian ageing: a critical appraisal. Mech Ageing Dev 2000;114:69-77.

33. Sozou PD, Seymour RM. To age or not to age. Proc Biol Sci 2004;271:457-63.

34. Gosain AK, Klein MH, Sudhakar PV, et al. A volumetric analysis of soft-tissue changes in the aging midface using high-resolution MRI: implications for facial rejuvenation. Plast Reconstr Surg 2005;115:1143-52.

35. Montagna W, Carlisle K. Structural changes in ageing skin. Br J Dermatol 1990;122 Suppl 35:61-70. 
36. Mendelson BC, Jacobson SR. Surgical anatomy of the midcheek: facial layers, spaces, and the midcheek segments. Clin Plast Surg 2008;35:395-404.

37. Rohrich RJ, Pessa JE. The fat compartments of the face: anatomy and clinical implications for cosmetic surgery. Plast Reconstr Surg 2007;119:2219-27.

38. Ghassemi A, Prescher A, Riediger D, et al. Anatomy of the SMAS revisited. Aesthetic Plast Surg 2003;27:258-64.

39. Gosain AK, Yousif NJ, Madiedo G, et al. Surgical anatomy of the SMAS: a reinvestigation. Plast Reconstr Surg 1993; 92:1254-63.

40. Moss CJ, Mendelson BC, Taylor GI. Surgical anatomy of the ligamentous attachments in the temple and periorbital regions. Plast Reconstr Surg 2000;105:1475-90.

41. Muzaffar AR, Mendelson BC, Adams WP Jr. Surgical anatomy of the ligamentous attachments of the lower lid and lateral canthus. Plast Reconstr Surg 2002;110:873-84.

42. Kahn DM, Shaw RB Jr. Aging of the bony orbit: a three-dimensional computed tomographic study. Aesthet Surg J 2008; 28:258-64.

43. Pessa JE, Zadoo VP, Mutimer KL, et al. Relative maxillary retrusion as a natural consequence of aging: combining skeletal and soft-tissue changes into an integrated model of midfacial aging. Plast Reconstr Surg 1998;102:205-12.

44. Shaw RB Jr, Kahn DM. Aging of the midface bony elements: a three-dimensional computed tomographic study. Plast Reconstr Surg 2007;119:675-81.

45. Bettman AG. Plastic and cosmetic surgery of the face. Northwest Med 1920;19:205.

46. Gibson T, Kenedi RM. Biomechanical properties of skin. Surg Clin North Am 1967;47:279-94.

47. Park DM. Total facelift: forehead lift, midface lift, and neck lift. Arch Plast Surg 2015;42:111-25.

48. Tonnard PL, Verpaele A, Gaia S. Optimising results from minimal access cranial suspension lifting (MACS-lift). Aesthetic Plast Surg 2005;29:213-20.
49. Verpaele A, Tonnard P, Gaia S, et al. The third suture in MACSlifting: making midface-lifting simple and safe. J Plast Reconstr Aesthet Surg 2007;60:1287-95.

50. Baker DC. Lateral SMASectomy. Plast Reconstr Surg 1997; 100:509-13.

51. Baker TJ, Stuzin JM. Personal technique of face lifting. Plast Reconstr Surg 1997;100:502-8.

52. Hamra ST. Composite rhytidectomy. Plast Reconstr Surg 1992;90:1-13.

53. Hamra ST. Composite rhytidectomy. Finesse and refinements in technique. Clin Plast Surg 1997;24:337-46.

54. Hamra ST. Composite rhytidectomy and the nasolabial fold. Clin Plast Surg 1995;22:313-24.

55. Tessier P. Facial lifting and frontal rhytidectomy. In: Fonseca J, editor. Transactions of the VII International Congress of Plastic and Reconstructive Surgery. Rio de Janeiro: Cartgraf; 1979. p.393-6.

56. Tessier P. Subperiosteal face-lift. Ann Chir Plast Esthet 1989; 34:193-7.

57. Ramirez OM. Endoscopic full facelift. Aesthetic Plast Surg 1994;18:363-71.

58. Ramirez OM. Three-dimensional endoscopic midface enhancement: a personal quest for the ideal cheek rejuvenation. Plast Reconstr Surg 2002;109:329-40.

59. Ramirez OM. The central oval of the face: tridimensional endoscopic rejuvenation. Facial Plast Surg 2000;16:283-98.

60. Ramirez OM. Full face rejuvenation in three dimensions: a "face-lifting" for the new millennium. Aesthetic Plast Surg 2001;25:152-64.

61. Ramirez OM. Facelift: subperiosteal facelift. In: Neligan PC, editor. Plastic surgery. New York: Saunders Elsevier; 2013. p.266-76.

62. Lee Y, Hong JJ. Multiplane face lift with the subperiosteal dissection for orientals. Plast Reconstr Surg 1999; 104:23744. 